\title{
IL28B rs12979860 Gene Polymorphism in Egyptian Patients with Chronic Liver Disease Infected with HCV
}

\author{
Abdel-Rahman N Zekri' ${ }^{*}$, Hosny Salama ${ }^{2}$, Eman Medhat ${ }^{2}$, Abeer A Bahnassy ${ }^{3}$, \\ Heba M Morsy ${ }^{1}$, Mai M Lotfy ${ }^{1}$, Rasha Ahmed ${ }^{2}$, Tarneem Darwish ${ }^{4}$, Mohamad \\ S Marei ${ }^{2}$
}

\begin{abstract}
Background: Egypt has one of the highest prevalences of hepatitis $\mathrm{C}$ virus (HCV) infection worldwide. Although the IL28B gene polymorphism has been shown to modify the course of chronic HCV infection, this has not been properly assessed in the Egyptian population. Materials and Methods: The IL28B rs12979860 single nucleotide polymorphism (SNP) was therefore examined in $256 \mathrm{HCV}$-infected Egyptian patients (group II) at different stages of disease progression and in 48 healthy volunteers (group I). Group II was subdivided into GII-A (chronic hepatitis patients, $n=119$ ), GII-B (post hepatitis cirrhosis, $n=66$ ) and GII-C (HCC on top of cirrhosis, $\mathrm{n}=71)$. Results: The $\mathrm{C} / \mathrm{T}$ genotype was the commonest in all groups. It was more frequent in GI (52\%) than in GII (48\%). There was no significant difference in the frequency of $\mathrm{C} / \mathrm{T}$ and $\mathrm{C} / \mathrm{C}$ or $\mathrm{T} / \mathrm{T}$ genotypes between groups and subgroups $(\mathrm{p}=0.82)$. Within the subgroups; the $\mathrm{C} / \mathrm{C}$ genotype was more common in GII-B while $\mathrm{C} / \mathrm{T}$ and $\mathrm{T} / \mathrm{T}$ genotypes were more common in GII-C, though with no significant difference $(p=0.59$ and $p=0.80)$. There was no significant association between IL28B rs12979860 SNP and viral load, ALT, AFP level, METAVIR scores for necro-inflammation and fibrosis, and Child-Pugh classification. Conclusions: 1) IL28Brs12979860 C/T genotype is the commonest genotype in HCV-associated CH and HCC in Egypt. 2) IL28Brs12979860 polymorphisms are not associated with disease progression or aggression (histological staging, severity of fibrosis in $\mathrm{CH}$ or the incidence of post-HCV HCC). 3) Differences in IL28Brs12979860 genotypes could be a consequence of environmental or ethnic variation.
\end{abstract}

Keywords: HCV - IL28B gene (rs12979860) polymorphism - chronic hepatitis - hepatocellular carcinoma

Asian Pac J Cancer Prev, 15 (17), 7213-7218

\section{Introduction}

The prevalence of hepatitis C virus (HCV) in Egypt exceeds $18 \%$ of the general population. Thus, with a population of more than 80 million, Egypt is considered to have the highest prevalence of hepatitis $\mathrm{C}$ in the world and consequently a high frequency of hepatocellular carcinoma (HCC) (Zekri et al., 2012; 2013). It was shown that, approximately $30 \%$ of infected individuals clear the viral infection naturally while $70 \%$ develop chronic disease that may finally lead to liver cirrhosis (LC) and/or hepatocellular carcinoma (HCC) (Morgan, 2011; Cheng et al., 2012). Several immunological factors are implicated in the determination of disease outcome in HCV infected patients including the adaptive immune response and the innate immune system, which regulate disease progression in those patients (Rehermann, 2009; Zekri et al., 2010). The contribution of the innate immune system to disease outcome in $\mathrm{HCV}$ infected patients was further supported by a series of studies on single nucleotide polymorphisms (SNPs) in the IL28B gene region, which predicts spontaneous and type 1 IFN induced clearance of HCV infections (Rauch et al., 2010).

Multiple genome-wide association studies (GWAS) have recently identified SNPs near the IL28B gene (encoding IFN- $\lambda 3$ ), which are strongly associated with spontaneous and treatment-induced clearance of $\mathrm{HCV}$ infections (Rauch et al., 2010). One of these SNPs is rs $12979860 \mathrm{C} / \mathrm{T}$, it is pivotal in predicting the outcome of HCV infections (Thomas et al., 2009). In El-Awady et al. (2012), it was demonestrated that genotype $\mathrm{C} / \mathrm{C}$ is significantly associated with viral clearance during the acute stage of HCV infection. The sharp decline in the $\mathrm{C} / \mathrm{C}$ genotype from healthy to $\mathrm{CHC}$ subjects and the total absence of the $\mathrm{C} / \mathrm{C}$ genotype in end stage liver disease, which were reported in this study, indicated a pivotal role of this genotype against disease progression in $\mathrm{HCV}$ infected patients. However, the data available in this area

${ }^{1}$ Virology and Immunology Unit, Cancer Biology Department, ${ }^{2}$ Tropical Medicine Department, Faculty of Medicine, ${ }^{3}$ Pathology Department, National Cancer Institute, ${ }^{4}$ Biomedical Informatics and Biostatistics, Faculty of Medicine, Cairo University, Cairo, Egypt*For correspondence: ncizekri@yahoo.com 
are still preliminary, especially in Egypt, and needs to be confirmed in larger studies.

The present study was conducted to determine the frequency of IL-28B rs12979860 gene polymorphism(s) and its contribution to disease progression in HCV infected patients from Egypt at various disease stages (chronic hepatitis without cirrhosis, chronic hepatitis with cirrhosis and hepatocellular carcinoma).

\section{Materials and Methods}

\section{Patients}

Patients were recruited from the Tropical Medicine Department in Kaser El-Aini school of medicine as well as INational Cancer Institute, Cairo University, Cairo, Egypt. Egypt during the period from May 2011 to May 2013, selection of the patients were done according to the approval of the patients to write the informed consent and to be enrolled in the study. The present study was conducted on 304 subjects who were categorized into two groups: group I (GI), which included 48 healthy volunteers and group II (GII), which included 256 chronic $\mathrm{HCV}$ infected patients with positive anti-HCV antibody at different disease stages. Patients with chronic GII $\mathrm{HCV}$ infection fulfilling the inclusion criteria: patients 18-60 years with positive anti-HCV and HCV RNA in serum while patients with any other cause of liver disease other than $\mathrm{HCV}$, other malignancies, family history of malignancy and/or patients with contraindication for liver biopsy were excluded. A written Informed consent to participate in the study was obtained from each patients and control subjects prior to enrolment in the study and the Institutional Review Boards (IRBs) of Kasr-AlAini Hospital and the National Cancer Institute, Cairo University, approved the study protocol which was in accordance with the 2007 Declaration of Helsinki and its appendices, and with local national laws. In addition, all study participants approved the storage of their frozen DNA specimens in our laboratory for research purposes.

Patients within group II were further subdivided into three subgroups according to the stage of the liver disease as follow

GIIA, included 119 chronic HCV patients with no evidence of liver cirrhosis and persistent normal liver profile with no hepatic abnormality by abdominal ultrasonography and f0 or f1 fibrosis by liver biopsy. the stage of fibrosis was assessed METAVIR score system. GIIB included 66 patients with post HCV liver cirrhosis (either compensated or decompensated according the modified Child-pugh score) who were diagnosed based on the presence of F4 in the liver biopsies (in 15 patients) or the presence of pertinent imaging features and laboratory findings in the rest of the patients. GIIC included 71 patients with HCC post HCV liver cirrhosis, who were diagnosed by hisopathological examination of biopsies taken from the focal lesions under US guidance according to BCLC guidelines (Bruix and Sherman, 2011). All relevant clinical and laboratory data are illustrated in Table 1.

\section{Clinical and laboratory workup}

All studied patients were subjected to proper history taking, full clinical evaluation, and laboratory investigations including: liver biochemical profile (serum bilirubin, serum albumin, INR, ALT, alkaline phosphatase and GGT), complete blood picture (CBC), alpha fetoprotein (AFP), viral Hepatitis serological profile (detection of HBV surface antigen [HBsAg], HCV antibody and anti $\mathrm{HBcAb}$ [total]) were done by using Axyam-Abbot and detection of HCV-RNA by PCR , AlfaFetoprotein (AFP), ANA. Abdominal ultrasonographic examination was done for all the enrolled patients using a Toshiba machine with a $3.5 \mathrm{MHZ}$ convex probe to assess the hepatic echo pattern, spleen size, portal circulation, portal tract thickening, and the presence of ascites and/or hepatic focal lesions after at least 8 hours fasting.

\section{Detection of the IL-28B rs12979860 polymorphism}

Genomic DNA was extracted from the blood samples of all subjects using commercially available DNA extraction kits. Genotyping for the IL-28B rs $12979860 \mathrm{C} / \mathrm{T}$ polymorphism was performed by a PCR-based restriction fragment length polymorphism assay as previously described in (Fabris et al., 2011). A 242 base pair product was obtained using the forward primer 5'-GCTTATCGCATACGGCTAGG-3', and the reverse primer 5'-AGGCTCAGGGTCAATCACAG-3' in a total volume of $20 \mu \mathrm{L}$ containing: $10 \mathrm{ng}$ of genomic DNA, $10 \mathrm{mM}$ Tris- $\mathrm{HCl}$ (pH 8.3), 50mM KCl, $0.01 \%$ Tween-20,0.2mM deoxyribonucleotides, $24 \mathrm{pmol}$ of each primer, 2.0mM $\mathrm{MgCl}_{2}$, and 0.5U Hot-Start Taq DNA polymerase. The PCR cycles were as follows: 40 cycles of denaturation (at $95^{\circ} \mathrm{C}$ for $30 \mathrm{~s}$ ), annealing (at $62^{\circ} \mathrm{C}$ for $30 \mathrm{~s}$ ) and elongation (at $72^{\circ} \mathrm{C}$ for $30 \mathrm{~s}$ ) using a Biometra $\mathrm{T} 1$ thermocycler. Ten microliters of the amplicons were digested with $1 \mathrm{U}$ of the BstU-I restriction endonuclease at $60^{\circ} \mathrm{C}$ overnight. The digested fragments were 135,82 and $25 \mathrm{bp}$ for the $\mathrm{C}$ allele and 160 and $82 \mathrm{bp}$ for the $\mathrm{T}$ allele variants. The fragments were resolved by electrophoresis in an ethidium bromide- stained $3.5 \%$ agarose gel.

\section{Statistical methods}

Patients' data were analysed using SPSS 17.0 for windows 7. Quantitative variables were expressed by mean \pm SD (Standard deviation) and compared using unpaired t-student test, Mann-Whitney test and KruskalWallis $\mathrm{H}$ test as appropriate. Qualitative variables were expressed by numbers (Frequency) and percent compared between groups using Chi-square test. The chi-square G test "Goodness of Fit" was employed to verify whether the proportions of the polymorphism were distributed both in patients and controls and in accordance with the Hardy-Weinberg equation. P-value was considered to be significant if less than 0.05. Upon analysing the contribution of (correlation between) IL-28B rs $12979860 \mathrm{C} / \mathrm{T}$ and disease progression, all factors that may contribute to- or considered as risk factor for HCC development such as chronic alcohol intake, diabetes mellitus (DM), high BMI, and other metabolic factors or co-infections were excluded. 


\section{Results}

Demographic, clinical and laboratory data of the studied groups are represented in Table 1. IL-28 rs $12979860 \mathrm{C} / \mathrm{T}$ polymorphism in both studied groups is illustrated in Table 2, Figure 1, and 2. The results showed that the polymorphism genotype frequencies in controls and patients didn't differ significantly where they were represented as follow: $\mathrm{C} / \mathrm{C}$ in controls " $29.2 \%$ " vs $\mathrm{C} / \mathrm{C}$ in patients " $33.6 \%$ ", $\mathrm{C} / \mathrm{T}$ in controls " 52 " \% vs $\mathrm{C} / \mathrm{T}$ in patients " $48 \%$ " and $\mathrm{T} / \mathrm{T}$ in controls " $18.8 \%$ " vs T/T in "18.4\%" respectively ( $\mathrm{p}$ value $=0.82$ ).

Studied patients were further categorized into subgroups according to the stage of the disease progression as follows: group IIA: $n=119$ representing chronic hepatitis $\mathrm{C}$ virus infected patients with no liver cirrhosis, group IIB: $\mathrm{n}=66$ patients with post-hepatitis $\mathrm{C}$ virus liver cirrhosis, group IIC: $\mathrm{n}=71$ patients with $\mathrm{HCC}$ post hepatitis $\mathrm{C}$ virus cirrhotic liver. The IL-28 rs12979860 C/T polymorphism were studied in these groups as well as in the control group and it was reported that in control subjects, the genotype frequencies did not depart from those expected on the basis of Hardy-Weinberg equilibrium (p-value=0.71), the same issue was observed in the other studied groups with p-values $=0.87,0.94$ and 0.59 for $\mathrm{CH}$ "Group II A", cirrhotic and HCC groups respectively.

After comparing the studied group of patients and controls, it was an evident that the presence of the $\mathrm{CC}$ genotype is associated with $\mathrm{CH}$ "Group II A" but this association is not statistically significant with $\mathrm{p}$-value $=0.66$, the same goes for cirrhotic patients with $\mathrm{p}$-value $=0.35$. but regarding the $\mathrm{HCC}$ patients there was association between TT genotype and HCC but also this association is not statistically significant with $\mathrm{p}$-value $=0.69$. Also when comparing patients with group IIC (HCC) to those with other HCV infected patients (group II A and B) an association between genotype TT

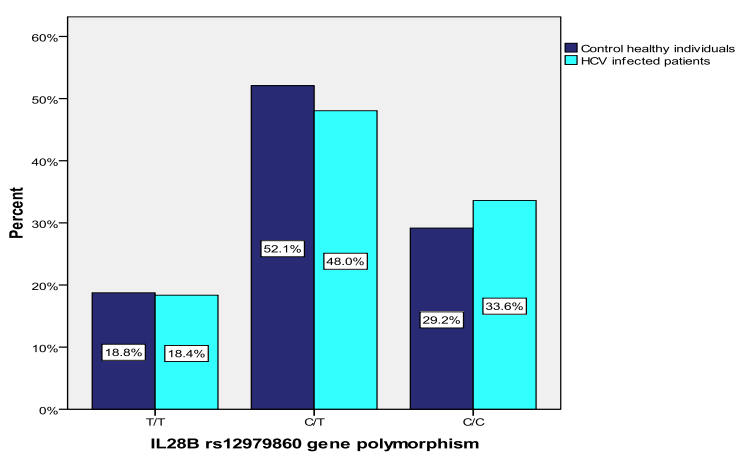

Figure 1. IL-28 Polymorphism among whole Studied Group of Patients and Healthy Volunteers

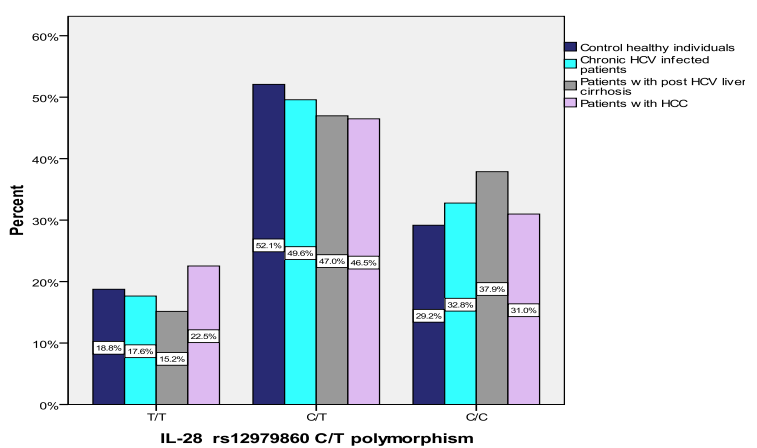

Figure 2. IL-28 Polymorphism among Studied Groups

Table 1. Main Demographic and Clinical Parameters of the Studied Population

\begin{tabular}{|c|c|c|c|c|c|c|}
\hline & & \multirow{2}{*}{$\begin{array}{l}\text { Control group } \\
\qquad(n=48)\end{array}$} & \multicolumn{3}{|c|}{ HCV infected patients $(n=256)$} & \multirow[t]{2}{*}{$\mathrm{p}$-value } \\
\hline & & & $\begin{array}{c}\text { Group II A } \\
\text { (chronic hepatitis) } \\
n=119\end{array}$ & $\begin{array}{c}\text { Group II B } \\
\text { (Liver cirrhosis) } \\
n=66\end{array}$ & $\begin{array}{l}\text { Group II C } \\
\text { (HCC) } \\
n=71\end{array}$ & \\
\hline Male gender & & $26(54.2 \%)$ & $84(76.4 \%)$ & $49(68.1 \%)$ & $41(57.7 \%)$ & $<0.05$ \\
\hline Age (years) & & $29.65 \pm 6.991$ & $39.08 \pm 8.925$ & $48.32 \pm 8.17$ & $54.35 \pm 6.806$ & $<0.001$ \\
\hline \multirow[t]{2}{*}{ Residence } & Rural & $13(27.1 \%)$ & $41(34.5 \%)$ & $15(22.7 \%)$ & $23(32.4 \%)$ & \multirow[t]{2}{*}{$>0.05$} \\
\hline & Urban & $35(72.9 \%)$ & $78(65.5 \%)$ & $51(77.3 \%)$ & $48(67.6 \%)$ & \\
\hline \multirow[t]{9}{*}{ Laboratory data } & Hemoglobin & & $13.91 \pm 1.43$ & $11.34 \pm 2.14$ & $11.26 \pm 1.59$ & $<0.001$ \\
\hline & TLC & & $2.46 \pm 3.52$ & $5.55 \pm 2.15$ & $5.36 \pm 1.95$ & $<0.001$ \\
\hline & PLT & & $202.44 \pm 63.28$ & $121.66 \pm 53.33$ & $114.71 \pm 42.336$ & $<0.001$ \\
\hline & T. Bilirubin & & $0.76 \pm 0.28$ & $2.37 \pm 1.86$ & $1.88 \pm 1.19$ & $<0.001$ \\
\hline & ALT & & $50.37 \pm 38.53$ & $58.6 \pm 36.99$ & $68.15 \pm 47.36$ & $<0.05$ \\
\hline & AST & & $39.25 \pm 16.8$ & $70.15 \pm 36.1$ & $78.08 \pm 52.04$ & $<0.001$ \\
\hline & Albumin & & $4.36 \pm 0.43$ & $3.22 \pm 0.76$ & $3.22 \pm 0.57$ & $<0.001$ \\
\hline & INR & & $1.15 \pm 0.26$ & $1.61 \pm 0.41$ & $1.44 \pm 0.305$ & $<0.001$ \\
\hline & AFP & & $4.34 \pm 4.1$ & $33.36 \pm 31.3$ & $1055.6 \pm 7221.1$ & $>0.05$ \\
\hline
\end{tabular}

Table 2. IL-28 rs12979860 Polymorphism in Both Studied Groups

\begin{tabular}{|c|c|c|c|c|c|c|c|}
\hline & \multicolumn{3}{|c|}{ Genotype } & \multirow[t]{2}{*}{ p-value* } & \multicolumn{2}{|c|}{ Allele } & \multirow[t]{2}{*}{ p-value* } \\
\hline & $\mathrm{T} / \mathrm{T}$ & $\mathrm{C} / \mathrm{T}$ & $\mathrm{C} / \mathrm{C}$ & & $\mathrm{T}$ & $\mathrm{C}$ & \\
\hline Control Group $(n=48)$ & $9(18.8 \%)$ & $25(52.1 \%)$ & $14(29.2 \%)$ & & $43(44.80 \%)$ & $53(55.2)$ & \\
\hline HCV Infected Patients $(n=256)$ & $47(18.4 \%)$ & $123(48.0 \%)$ & $86(33.6 \%)$ & 0.82 & $217(42.40 \%)$ & $295(57.6 \%)$ & 0.66 \\
\hline Chronic Hepatitis $(n=119)$ & $21(17.6 \%)$ & $59(49.6 \%)$ & $39(32.8 \%)$ & 0.94 & $101(42.40 \%)$ & $137(57.50 \%)$ & 0.69 \\
\hline Liver Cirrhosis $(n=66)$ & $10(15.2 \%)$ & $31(47.0 \%)$ & $25(37.9 \%)$ & 0.59 & $51(38.70 \%)$ & $81(61.3)$ & 0.35 \\
\hline Hepatocellular Carcinoma $(n=71)$ & $16(22.5 \%)$ & $33(46.5 \%)$ & $22(31.0 \%)$ & 0.8 & $65(45.8)$ & $77(54.2)$ & 0.88 \\
\hline
\end{tabular}

*Compared to the control group 
Table 3. The Association between the IL-28 Polymorphism and the Stage of Liver Disease

\begin{tabular}{|c|c|c|c|c|c|c|}
\hline & & & \multicolumn{3}{|c|}{ IL-28 rs12979860 polymorphism } & \multirow[t]{2}{*}{$\mathrm{p}$-value } \\
\hline & & & $\mathrm{T} / \mathrm{T}$ & $\mathrm{C} / \mathrm{T}$ & $\mathrm{C} / \mathrm{C}$ & \\
\hline \multirow{6}{*}{$\overline{\text { ALT level }}$} & \multirow[t]{2}{*}{ Chronic hepatitis (group II A) $(\mathrm{n}=119)$} & $0-41 *$ & $9(17 \%)$ & $29(54.7 \%)$ & $15(28.3 \%)$ & \multirow[t]{2}{*}{0.52} \\
\hline & & $>41$ & $12(18.5 \%)$ & $29(44.6 \%)$ & $24(36.9 \%)$ & \\
\hline & \multirow{2}{*}{ Liver cirrhosis (group II B) $(n=66)$} & $0-41$ & $2(10.5 \%)$ & $12(63.2 \%)$ & $5(26.3 \%)$ & \multirow[t]{2}{*}{0.27} \\
\hline & & $>41$ & $7(15.9 \%)$ & $18(40.9 \%)$ & $19(43.2 \%)$ & \\
\hline & \multirow[t]{2}{*}{ Hepatocellular carcinoma (group II C) $(\mathrm{n}=71)$} & $0-41$ & $2(10 \%)$ & $10(50 \%)$ & $8(40 \%)$ & \multirow[t]{2}{*}{0.23} \\
\hline & & $>41$ & $14(27.5 \%)$ & $23(45.1 \%)$ & $14(27.5 \%)$ & \\
\hline \multirow[t]{2}{*}{ AFP level } & \multirow[t]{2}{*}{ Hepatocellular carcinoma (group II C) $(n=71)$} & $<200$ & $12(22.6 \%)$ & $21(39.6 \%)$ & $20(37.7 \%)$ & \multirow[t]{2}{*}{0.24} \\
\hline & & $\geq 200$ & $4(28.6 \%)$ & $8(57.1 \%)$ & $2(14.3 \%)$ & \\
\hline \multirow[t]{2}{*}{ Viral load } & \multirow{2}{*}{$\begin{array}{l}\text { HCV infected patients }(\mathrm{n}=256) \\
(\text { mean } \pm \text { SD })\end{array}$} & & $951704.73 \pm$ & $1289718.47 \pm$ & $1512236.47 \pm$ & \multirow[t]{2}{*}{0.66} \\
\hline & & & 1418703.481 & 2794576.829 & 2310777.054 & \\
\hline \multirow[t]{4}{*}{ Child-Pugh classification } & \multirow[t]{2}{*}{ Liver cirrhosis (group II B) (n=66) } & A & $3(11.5 \%)$ & $12(46.2 \%)$ & $11(42.3 \%)$ & \multirow[t]{2}{*}{0.74} \\
\hline & & $\mathrm{B} \& \mathrm{C}$ & $7(17.5 \%)$ & $19(47.5 \%)$ & $14(35.0 \%)$ & \\
\hline & \multirow[t]{2}{*}{ Hepatocellular carcinoma (group II C) $(n=71)$} & A & $9(22.5 \%)$ & $20(50.0 \%)$ & $11(27.5 \%)$ & \multirow[t]{2}{*}{0.7} \\
\hline & & $\mathrm{B} \& \mathrm{C}$ & $7(22.6 \%)$ & $13(41.9 \%)$ & $11(35.5 \%)$ & \\
\hline \multirow[t]{2}{*}{ Fibrosis score } & $\mathrm{F} 0 / \mathrm{F} 1$ & & $16(18.2 \%)$ & $42(47.7 \%)$ & $30(34.1 \%)$ & \multirow[t]{2}{*}{0.7} \\
\hline & $\mathrm{F} 2 / \mathrm{F} 3 / \mathrm{F} 4$ & & $7(13.2 \%)$ & $26(49.1 \%)$ & $20(37.7 \%)$ & \\
\hline
\end{tabular}

*Normal ALT level up to 0-41 IU/ml

and HCC patients was reported where $22.5 \%$ of patients with HCC had genotype TT while $16.8 \%$ of other patients are TT genotype but this association is not statistically significant with $\mathrm{p}$-value $=0.28$ as well.

On comparing the allele frequency between the controls and other studied groups it was reported that $\mathrm{C}$ allele was associated with cirrhotic patients $61.3 \%$ but this association is not statistically significant with $\mathrm{p}$-value $=0.35$, while the $\mathrm{T}$ allele frequency was relatively higher in HCC patients $(45.8 \%)$ compared to the other studied groups but with no statistically significance.

Regarding the viral load in patients of group II having $\mathrm{CC}$ genotype it was reported to be greater than those having CT and TT genotypes but this difference was not statistically significant with p-values $=0.66,0.19$, the viral load in patients having CT genotype is greater than those having TT genotypes but this difference is not statistically significant with p-value $=0.55$.

Regarding the tumour marker (AFP) assessed in our study, our results revealed that in HCC patients there was an association between AFP levels less than 200 and genotype CC (37.7\% of patients with level less than 200 were CC) but this association is not statistically significant, while an association was noticed between AFP levels above 200 and genotype CT $57.1 \%$ of patients with AFP level above 200 were CT) but this association is not statistically significant as well.

IL-28 rs12979860 C/T polymorphism showed no statistically significant association with the liver fibrosis score (Table-3) where $47.7 \%$ of patients with low fibrosis stage $(<\mathrm{F} 2)$ and $49.1 \%$ of patients with high fibrosis stage $(\geq \mathrm{F} 2)$ were of $\mathrm{C} / \mathrm{T}$ genotype ( $\mathrm{p}$-value $=0.70)$.

No statistically significant association reported between the ALT level and the IL-28 rs12979860 C/T polymorphism in the studied group of patients, where patients of $\mathrm{CH}$ (group II A) showed association between the $\mathrm{C} / \mathrm{C}$ genotype and $\mathrm{ALT} \geq 41$ and patients of group IIB (Cirrhotic patients) showed association between the $\mathrm{C} / \mathrm{C}$ genotype and ALT $\geq 41$ and patients of group IIC (HCC) showed association between the T/T genotype and ALT level $\geq 41$ with -values $=0.52,0.27$ and 0.23 respectively.

No statistically significant association reported between Child-Pugh classification score and the IL-28 rs12979860 C/T polymorphism in the studied group of patients. Patients of group IIB (liver cirrhosis) showed association between the T/T genotype and child-pugh score B and C (p-value $=0.74$ ) and patients of group IIC (HCC) showed association between $\mathrm{C} / \mathrm{T}$ genotype and Child-Pugh score A (p-value=0.72).

\section{Discussion}

The natural history of hepatitis $\mathrm{C}$ virus (HCV) infection varies greatly. However, it is still unclear to what extent do genetic variations at the IL28B locus contribute to the severity and time to progression in $\mathrm{HCV}$-associated liver disease (Marabita et al., 2011), especially in the Egyptian population, which has the highest prevalence of HCV infection worldwide.

Since the progression of $\mathrm{HCV}$ related liver disease could be related to many factors, other than the genetic background of the patients (Missiha et al., 2008), we excluded in the current study most of the factors that may contribute to disease progression or considered as risk factors for the development of HCC such as chronic alcohol intake, diabetes mellitus, high BMI and other metabolic disorders or co-infections (e.g. schistosomiasis, chronic HBV or even occult Hepatitis B infection).

The results of the current study show that the IL-28 rs12979860 CT genotype is the commonest genotype in patients and control groups. Within the normal control group, there was a statistically significant difference between the frequency of $\mathrm{C} / \mathrm{T}$ genotype and the other two genotypes $(\mathrm{C} / \mathrm{C}$ and $\mathrm{T} / \mathrm{T})$ suggesting a possible role for this genotype in the transition of a normal hepatocyte into an abnormal one.

Within group II ( $\mathrm{CH}$ and $\mathrm{HCC})$, the $\mathrm{CT}$ and TT genotypes were common in $\mathrm{HCC}$, whereas the $\mathrm{CC}$ genotype was more common in $\mathrm{CH}$ (group II A) patients, though these associations did not reached a statistically significant level. One possible reason for the lack of any significant relation between the IL-28 rs12979860 genotype and the disease stage could be the relatively small sample size within each subgroup. A second reason 
could be the high frequency of the CT genotype which neutralizes the effect of the other two genotypes.

Our results regarding the high frequency of the TT genotype in HCC group confirm the results of (Falleti et al., 2011) who reported a significantly higher frequency of the T/T allele in chronic $\mathrm{HCV}$-infected patients from Italy compared to non HCC patients (43.5\% and $31.0 \%$; respectively, $\mathrm{p}<0.05$ ) and it was significantly related to the severity of liver fibrosis. They also demonstrated that the $\mathrm{C} / \mathrm{C}$ allele was more frequent in the control group $(0.410$ versus 0.321 and $47.0 \%$ versus $32.6 \%$ ).

In this context, (Eurich et al., 2012) demonstrated that the TT genotype was more frequent in the explanted livers in $\mathrm{HCC}$ patients than in patients without $\mathrm{HCC}(\mathrm{p}=0.041)$, suggesting a protective role for the $\mathrm{C}$ allele against the development of HCC.

Our results regarding the frequency of the protective $\mathrm{C} / \mathrm{C}$ genotype (about $30 \%$ of the Egyptian healthy control) and the slightly higher frequency of the $\mathrm{C}$ than the $\mathrm{T}$ allele give the Egyptian population a near modest frequency of the protective (C) allele compared to its high frequencies in East Asian populations and its low frequencies in the sub-Saharan Africa (Thomas et al., 2009). This highlights the role of ethnic variation in relation to the genetic environment, which should be extensively explored in large, population based studies including larger numbers of patients and control subjects in order to determine the exact frequency and contribution of SNPs in different ethnic groups at different disease stages.

On the other hand, our data regarding the lack of a protective role of the $\mathrm{C} / \mathrm{C}$ genotype coincide with some previous studies on other populations. Apart from the statistically significant correlation between $\mathrm{C} / \mathrm{C}$ genotype and an AFP level $<200$, none of the tested clinical and laboratory determinants of disease aggression and/or progression in the current study showed a significant relation with $\mathrm{C} / \mathrm{C}$ genotype. (Thompson et al., 2010) did not find any association between rs 12979860 polymorphism and advanced hepatic fibrosis in HCV genotype 1 associated CHC patients enrolled in the IDEAL study. (Marabita et al., 2011) confirmed this finding on 247 Caucasian patients with chronic HCV infection, of these $96 \%$ were genotype 1 and $4 \%$ only were genotype 4 . According, they concluded that IL-28B genotype can't be considered a determinant for the development of advanced liver fibrosis. Similarly, (Asselah et al., 2012) were not able to find any significant relationship between IL28B rs 12979860 polymorphism and fibrosis stage or disease severity, though they reported a significant correlation between IL28B rs12979860 polymorphism and treatment. However, some recent studies showed that the IL-28B rs12979860 T/T genotype is an independent predictor of a higher fibrosis staging score compared to the $\mathrm{CC}$ or CT genotypes (Agundez et al., 2010; Falleti et al., 2011).

In the contrary, other studies demonstrated that patients with genotype 1, 2 or $3 \mathrm{HCV}$ and IL-28B rs12979860 $\mathrm{C} / \mathrm{C}$ genotype had higher pre-treatment ALT values and moderate-to-severe (METAVIR A2-A3) necroinflammatory activity (Sarrazin et al., 2011a; 2011b; Thompson et al., 2012).

The discrepancy in the results of different studies regarding the association between liver fibrosis stage and IL28B rs12979860 SNP polymorphism could be attributed to the HCV genotype in the studied population, the sample size or to ethnic and environmental variability.

We also found that IL28B rs 12979860 polymorphism does not contribute to the severity of the HCV infection or to the development of HCC in chronic HCV-infected Egyptian patients since there was no significant difference between the IL28B rs12979860 genotype frequencies within the different disease stages.

Based on the findings of the current study, we conclude that IL28B rs12979860 polymorphism have no effect on the progression of $\mathrm{HCV}$ associated liver disease or the incidence of HCC in the Egyptian population. This confirms previous studies which raised the issue of ethnic variations in addition to genetic and environmental factors as an explanation for the controversial results in the field of SNP (Zhang et al., 2014). This raises additional questions regarding the role of host genetic factors and the interaction between host and viral genotypes in the modulating disease progression. Further studies of the host genetic determinants associated with a risk of liver disease progression in HCV are still needed for better understanding of disease pathogenesis and improved patient-selection for antiviral therapy.

\section{References}

Agúndez JA, Garcia-Martin E, Maestro ML, et al (2012). Relation of IL28B gene polymorphism with biochemical and histological features in hepatitis $\mathrm{C}$ virus-induced liverdisease. PLoS One, 7, 37998.

Asselah T, De Muynck S, Broet P, et al (2012). IL28B polymorphism is associated with treatment response in patients with genotype 4 chronic hepatitis C. J Hepatol. 56, 527-32.

Bruix J, Sherman M (2011). Management of hepatocellular carcinoma: an update AASLD, practice guidelines. Hepatol, 53, 1020-2.

Cheng P, Cheng Y, Su MX, et al (2012). Bicluster and pathway enrichment analysis of HCV-induced cirrhosis and hepatocellular carcinoma. Asian Pac J Cancer Prev, 13, 3741-5.

El-Awady MK, Mostafa L, Tabll AA, et al (2012). Association of IL28B snp with progression of Egyptian HCV genotype 4 patients to end stage liver disease. Hepat Mon, 12, 271-7.

Eurich D, Boas-Knoop S, Bahra M, et al (2012). Role of IL28B polymorphism in the development of hepatitis C virus-induced hepatocelular carcinoma, graft fibrosis, and posttransplant activiral therapy. Transpl, 93, 644-9.

Fabris C, Falleti E, Cussigh A, et al (2011). IL-28B rs 12979860 $\mathrm{C} / \mathrm{T}$ allele distribution in patients with liver cirrhosis: role in the course of chronic viral hepatitis and the development of HCC. J Hepatol. 54, 716-22

Falleti E, Bitetto D, Fabris C, et al (2011). Role of interleukin 28B rs12979860 C/T polymorphism on the histological outcome of chronic hepatitis C: relationship with gender and viral genotype. J Clin Immunol, 31, 891-9.

Marabita F, Aghemo A, De Nicola S, et al (2011). Genetic variation in the interleukin-28B gene is not associated with fibrosis progression in patients with chronic hepatitis $\mathrm{c}$ and known date of infection. Hepatol, 54, 1127-34.

Missiha SB, Ostrowski M, Heathcote EJ (2008). Disease progression in chronic hepatitis $\mathrm{C}$ : modifiable and non- 
modifiable factors. Gastroenterol, 134, 1699-714.

Morgan TR (2011). Chemoprevention of hepatocellular carcinoma in chronic hepatitis C. Rec Results Cancer Res, 188, 85-99.

Rauch A, Kutalik Z, Descombes P, et al (2010). Genetic variation in IL28B is associated with chronic hepatitis $\mathrm{C}$ and treatment failure: a genome-wide association study. Gastroenterol, 138, 1338-45.

Rehermann B (2009). Hepatitis C virus versus innate and adaptive immune responses: a tale of co evolution and coexistence. J Clin Invest, 119, 1745-54.

Sarrazin C, Susser S, Doehring A, et al (2011). Importance of IL28B gene polymorphisms in hepatitis $\mathrm{C}$ virus genotype 2 and 3 infected patients. J Hepatol, 54, 1099-106.

Thomas DL, Thio CL, Martin MP, et al (2009). Genetic variation in IL28B and spontaneous clearance of hepatitis $\mathrm{C}$ virus. Nature, 461, 798-801

Thompson A, Clark PJ, Fellay J, et al (2010). IL28B genotype is not associated with advanced hepatic fibrosis in chronic hepatitis C patients enrolled in the IDEAL study. Hepatol, 52, 437

Thompson AJ, Clark PJ, Singh A, et al (2012). Genome-wide association study of interferon-related cytopenia in chronic hepatitis C patients. J Hepatol, 56, 313-9.

Zekri AR, Moharram RA, Mohamed WS, et al (2010). Disease progression from chronic hepatitis $\mathrm{C}$ to cirrhosis and hepatocellular carcinoma is associated with repression of interferon regulatory factor-1. Eur J Gastroenterol Hepatol, 22, 450-6.

Zekri A, Hassan Z, Bahnassy A, et al (2012). Molecular prognostic profile of Egyptian HCC cases infected with hepatitis C virus. Asian Pac J Cancer Prev, 13, 5433-8.

Zekri A, Nassar A, El-Rouby M, et al (2013). Disease progression from chronic hepatitis $\mathrm{C}$ to cirrhosis and hepatocellular carcinoma is associated with increasing DNA promoter methylation. Asian Pac J Cancer Prev, 14, 6721- 6

Zhang X-L, Lu Y, Yang S, et al (2014). An updated metaanalysis between the Association of XRCC1 Arg399Gln Polymorphism and Hepatocellular Carcinoma Risk. Asian Pac J Cancer Prev, 15, 3273-8. 